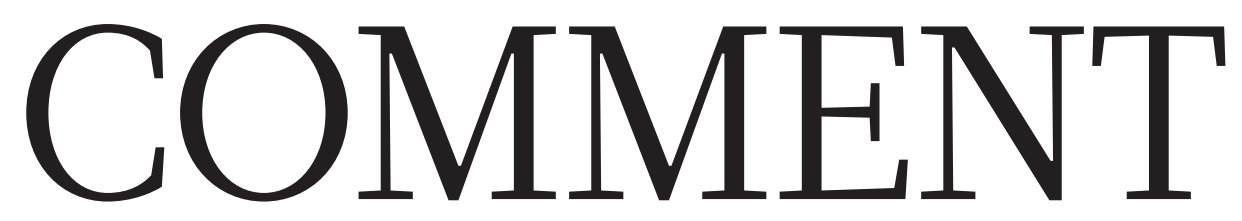
\begin{tabular}{l|l|l|l}
$\begin{array}{l}\text { ENERGY Governments must } \\
\text { keep backing the renewables } \\
\text { boom } \mathbf{p . 2 9 7}\end{array}$ & $\begin{array}{l}\text { HOMININS Was the hunt for } \\
\text { water the key driver in } \\
\text { human evolution? p.303 }\end{array}$ & $\begin{array}{l}\text { VISUALIZATION Exhibition } \\
\text { celebrates history of } \\
\text { scientific graphics p.304 }\end{array}$ & $\begin{array}{l}\text { REPRODUCIBILITY Hypothesis- } \\
\text { driven projects risk data } \\
\text { discounting } \mathbf{p . 3 0 6}\end{array}$
\end{tabular}

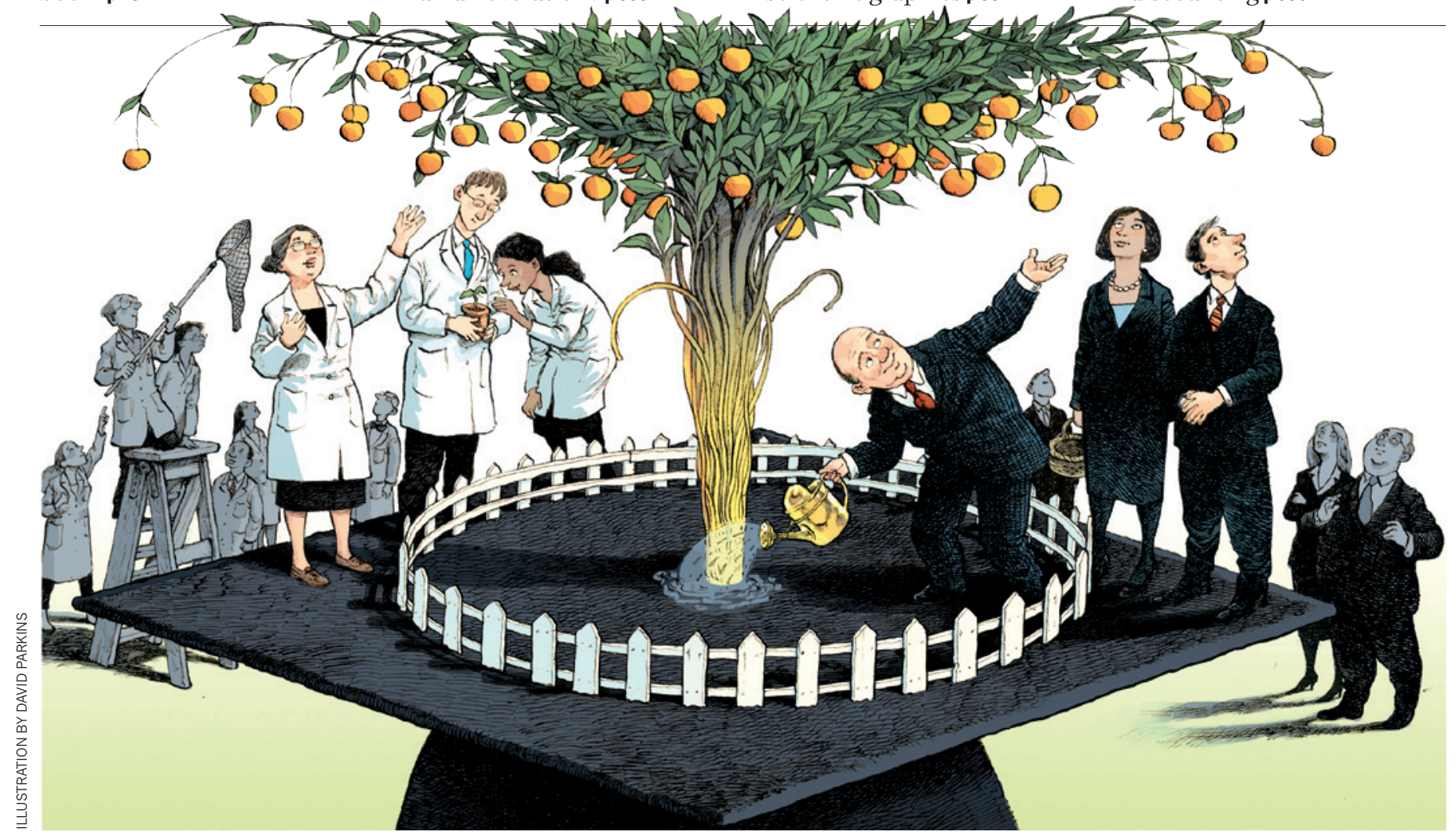

\title{
Industry-funded academic inventions boost innovation
}

Brian D. Wright and colleagues present data challenging the assumption that corporate-funded academic research is less accessible and useful to others.

\section{G} overnments have long encouraged university-industry collaboration, hoping to spur innovations that bring jobs, investment and life-enhancing products ${ }^{1}$. At the same time, shrinking government budgets for science have forced universities to look to other sources of funding. According to the US National Science Foundation, in 2012, industry supplied just over 5\% (some US $\$ 3.2$ billion) of US research universities' annual expenditure ${ }^{2}$.

But the role of corporations in academic research is controversial. For example, when oil company BP announced in 2007 that it would pay $\$ 500$ million to fund a decade of alternative-energy research by a consortium headed by the University of California, Berkeley, this prompted a backlash. Fearing that industry money would contaminate the public institution's research agenda, many students, staff and members of the community picketed the campus with a 2.5-metre Trojan horse. An earlier agreement between the department of plant and microbial biology at Berkeley and the Swiss pharmaceutical firm Novartis sparked similar opposition. At the 1999 graduation ceremony, about 100 students displayed the company's logo on their mortarboards, protesting that the department had been bought by corporate interests.
There are reasons to be cautious about corporate sponsorship of academic research ${ }^{3}$. The tobacco, food, pharmaceutical and other industries have been shown to manipulate research questions and public discourse for their own benefit and even to suppress unfavourable research ${ }^{4}$. And companies may shift university researchers towards narrow corporate interests. If the results of research are privately held, others cannot exploit them.

Conversely, some feel that overly restrictive university technology-transfer policies stifle productive deal-making between firms and academic researchers ${ }^{5}$. Some advocate that a university's intellectual property should $>$ 
$>$ be managed by an outside agency ${ }^{6}$, or else handed over directly to researchers or to the companies funding their work ${ }^{7}$.

Data to inform this debate are hard to come by. Individual universities may track patents and licences at their own institutions, but these data sets are generally small and confidential. The prevailing assumption is that corporate-sponsored inventions and the information associated with them are less accessible and less useful to others than inventions sponsored by the government or non-profit organizations.

Here we offer empirical evidence to the contrary. Our analysis suggests that corporate-sponsored research is surprisingly valuable for further innovation. Data collected over 20 years at nine campuses and three national laboratories administered by the University of California show that corporate-sponsored inventions are licensed and cited more often than federally sponsored ones.

Although results might differ at other academic institutions, these findings should allay concerns that corporate sponsorship turns leading universities into corporate vassals. Collecting and combining data from a larger sample of institutions could help to both explore what corporations hope to gain from funding academic work, and suggest how universities can best manage research sponsorships.

\section{TECHNOLOGY TRANSFER}

Like most universities, the University of California requires faculty members and other researchers to disclose any invention that has commercial potential to one of its offices of technology transfer (OTTs), and to list funding sources for the project that led to it. Under these terms, an invention is anything that a researcher feels could be patented or is otherwise valuable as intellectual property: it might be a material, a method, or an animal or plant. The OTT then determines whether to pursue intellectual property protection on the university's behalf and negotiates contracts with potential licensees.

From 1990 to 2005, University of California faculty members, staff and students, and employees of the three associated national laboratories disclosed 12,516 inventions to their OTTs. Of these, nearly 1,500 were supported, at least in part, by corporate funds. Under strict terms of confidentiality, the central OTT provided us with data on these disclosures, and on related licensing activities, until the end of 2010. From 1990 to 2010 the University of California campuses accounted for up to $9 \%$ of total US academic research expenditure. Collectively, they obtained more issued patents than any other US academic institution. In lists compiled annually by the US Patent and Trademark Office, the multi-campus
University of California system often had more than twice as many patents as academia (generally the Massachusetts Institute of Technology in Cambridge).

Of all inventions generated at the University of California, 20\% are linked to at least one licence, and nearly $25 \%$ were eventually patented. Inventions with no sponsor information were the least likely to yield either licences $(13 \%)$ or patents (17\%). We believe that most of these inventions came either without extramural support or with federal support, which is such a common situation that inventors or technology-transfer agents may not note it explicitly. Corporatesponsored inventions resulted in licences (29\%) and patents (35\%) more frequently than federally sponsored ones $(22 \%$ and $26 \%$, respectively). The rates are higher still for inventions with both types of sponsor; $36 \%$ were licensed and $43 \%$ patented (see 'Licensed and cited'). Results were similar across technical fields. More than two-thirds of classified technologies relate to biological, pharmaceutical and chemical advances, a distribution that is consistent with other leading research universities (for the complete results see Supplementary information; go.nature.com/o99eua).

Although corporate-sponsored inventions are more likely to be patented, that does not mean that corporate support makes inventions more patentable. Instead, corporations might select projects that are more likely to produce patentable inventions.

Corporations typically get priority to negotiate licences to the inventions they sponsor, and $86 \%$ of the licences to the sponsors are exclusive, meaning that the university agrees not to grant the same rights to multiple licensees. Of licensed inventions associated with some form of intellectual property, $78 \%$ were licensed exclusively, consistent with the share of $79 \%$ reported for licensing of patents the second-largest patent producer in

funded by the National Institutes of Health ${ }^{8}$.

Nevertheless, our analysis did not support our original assumptions that licences to industry-sponsored inventions would be likely to be exclusive, or that sponsors would snap up the lion's share of exclusive licences. First, the overall percentage of corporatesponsored inventions licensed exclusively (74\%) is not higher than for those with solely public funding (76\%). Second, half of the exclusive licences for corporate-sponsored inventions seem to be to third parties (although we cannot be sure that we identified all the sponsor-controlled firms in the data). Apparently, even the inventions that sponsors leave on the table have substantial value, because these licensees usually bear significant costs of patenting, plus agreements to pay future royalties.

Another surprise is that corporatesponsored inventions spur more 'knowledge spillovers', on average, than federally sponsored research, according to forward citation rates, the most widely used metric for patent quality and value. Forward citations show how many times one patent is cited in subsequent patents. Each corporate-sponsored invention generated, on average, 12.8 forward citations if licensed to a third party (more if licensed by the sponsor), compared with 5.6 for federally sponsored inventions. This runs counter to the expectation that corporatesponsored inventions have narrow applications, and so create more private benefits but few benefits for others.

\section{USING UNIVERSITIES}

This analysis does not address how corporate funds affect universities' research agendas, but it does dispute the idea that corporations tie up all sponsored inventions to restrict access. Instead, high patent citation rates for corporate-sponsored inventions suggest that firms are funding exploratory research. Work by sociologist James Evans

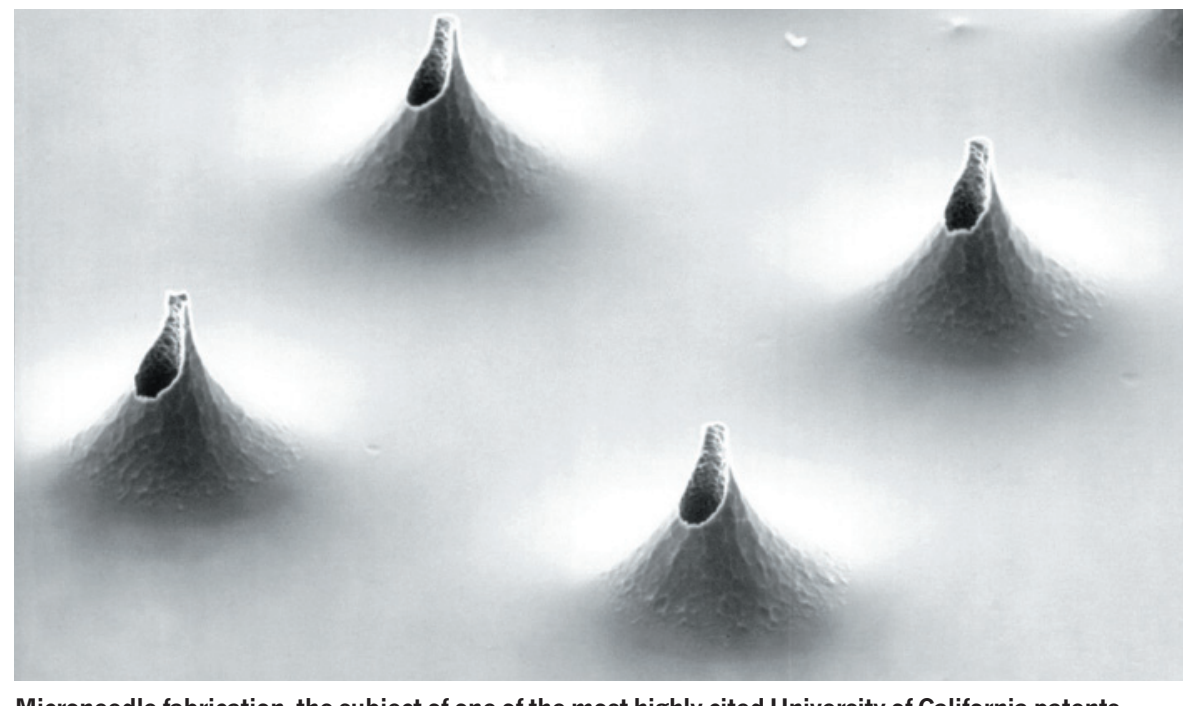

Microneedle fabrication, the subject of one of the most highly cited University of California patents. 


\section{LICENSED AND CITED}

Of the 12,516 inventions logged by technology-transfer offices of the University of California system between 1990 and 2005 , inventions with only federal funding were less likely to be patented or licensed than those with corporate or corporate and federal funding, and had lower patent citation rates.
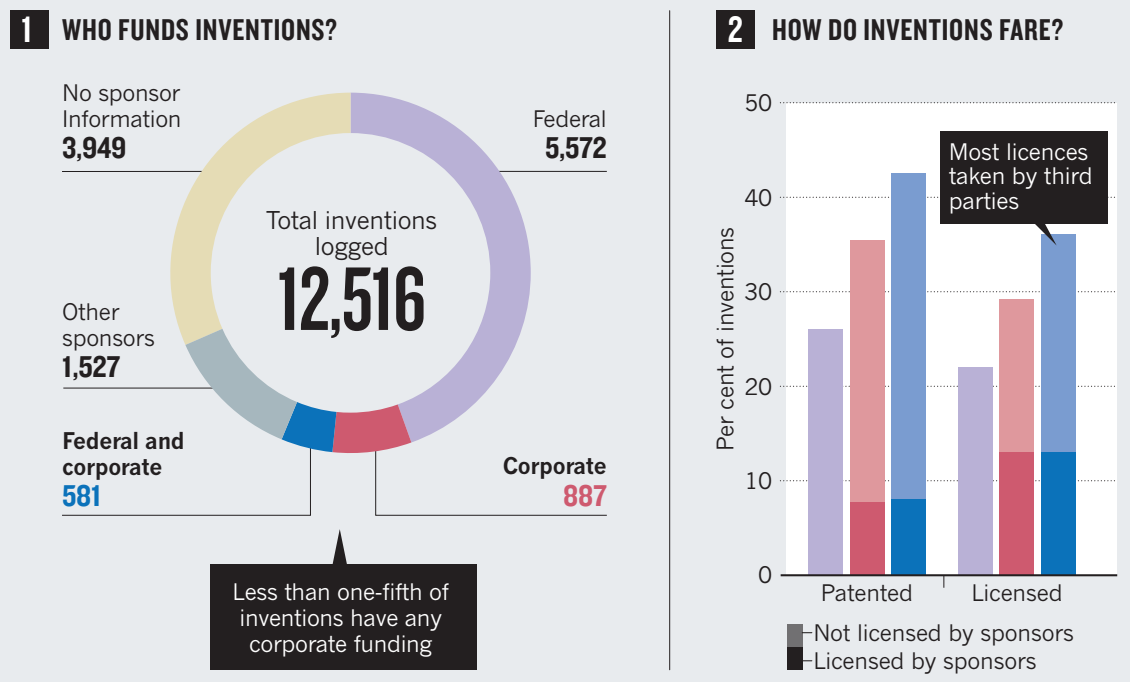

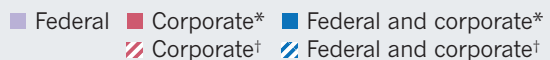

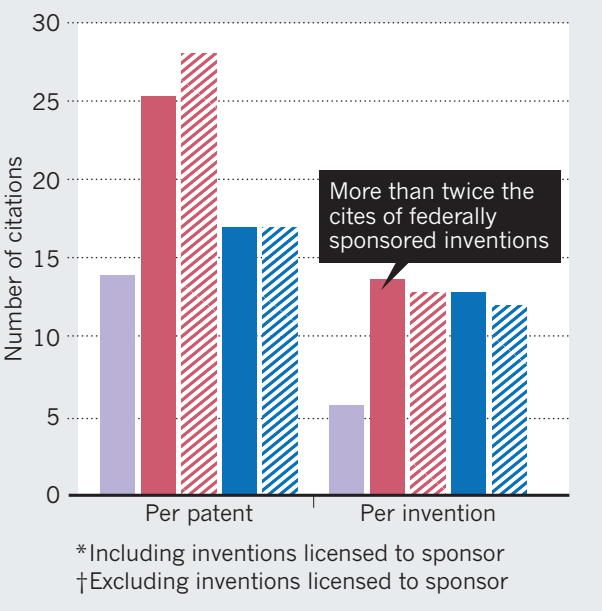

at the University of Chicago in Illinois suggests that corporations turn to universities to investigate areas outside their core strengths, investing in speculative science in the hope of finding profit opportunities ${ }^{9}$.

In fact, Evans argues that corporations actually urge academics to explore further afield than they might otherwise. Although academics may act conservatively to gain acceptance of peers, papers and grant proposals, he writes", "industry partnerships draw high-status academics away from confirming established theories and towards speculation".

For example, the \$500-million research grant from BP to the Berkeley-led consortium was intended to explore biofuels from cellulose in plants or crop residues, an area in which BP had virtually no expertise. In such cases, many resulting inventions might turn out to be informative to other researchers, but irrelevant to the firm's business strategy.

In such cases, other firms' subsequent work on an invention can be more valuable to sponsors than exclusive access. For example, preliminary work by Yongdong Liu, a $\mathrm{PhD}$ candidate at Berkeley, suggests that information-technology company IBM discloses innovations on the periphery of its expertise without patenting them, but often cites non-IBM patents building on the disclosed innovations. Similarly, some major drug companies contributed to the publicly funded Human Genome Project, reasoning that faster access to results would accelerate its ability to develop drugs, even if those results were openly available.

Acquiring intellectual property is not necessarily the prime focus of corporate sponsors. Companies also value sustained relationships with leading scientists and associated opportunities to identify and recruit talented employees. The University of California-Novartis agreement apparently generated no licences for the company, and Novartis representatives reportedly did not exert any apparent influence on the selection of projects it funded ${ }^{10}$.

Joint federal-corporate sponsorship may stem from more-focused goals. We understand that they often arise from projects initiated by federal funding agencies, with corporate sponsors recruited to develop early, promising work into practical applications. For example, if a federally sponsored gene-screening programme finds an attractive drug target, corporations might support projects to screen drug candidates against that target. This kind of focus would explain why inventions in this category are the most likely to be licensed (even by third parties) but not more highly cited.

The large share of third-party licences suggests that the University of California successfully markets inventions and also negotiates agreements to keep corporations from locking them up unduly. This task is probably facilitated by the fact that many sponsoring firms seem to recognize that sharing exploratory research can be in their own interests.

To assess whether these findings generalize to other academic institutions, data from other research universities are needed. We advocate a project to pool similar data from a large sample of other research universities, with solid confidentiality safeguards, for empirical analysis. Such work could evaluate whether, for instance, groups of smaller or less research-oriented institutions would be better served by outsourcing to a single technology-transfer institution.

Universities setting up contracts with corporations need to be vigilant in their mission to generate and transfer knowledge, but they should not assume that companies are focused mainly on tying up intellectual property. Those that do will miss fruitful opportunities for collaboration with firms willing to fund projects from which many others will probably benefit.

Brian D. Wright is professor of agricultural and resource economics at the University of California, Berkeley, USA. Kyriakos Drivas is a postdoctoral research economist at the Agricultural University of Athens, Greece, and a research fellow at the University of Piraeus, Greece. Zhen Lei is assistant professor of energy and environmental economics at the Pennsylvania State University in University Park, USA. Stephen A. Merrill directs the US National Academy of Sciences' Program on Science, Technology, and Economic Policy in Washington DC, USA.

e-mail:bwright@berkeley.edu

1. President's Council of Advisors on Science and Technology University-Private Sector Research Partnerships in the Innovation Ecosystem (OSTP, 2008); available at http://go.nature.com/hilyum.

2. National Science Board Science and Engineering Indicators 2014 5-13 (NSF, 2014).

3. Washburn, J. University, Inc: The Corporate Corruption of Higher Education (Basic Books, 2005).

4. White, J. \& Bero, L. A. Stanford Law Policy Rev. 21 , 105-133 (2010).

5. Kramer, D. Physics Today 61, 20-22 (2008)

6. Litan, R., Mitchell, L. \& Reedy, E. J. Innov. Policy Econ. 8, 31-57 (2008).

7. Foley, H. C. Res. Technol. Mgmt 55, 12-17 (2012)

8. Pressman, L. et al. Nature Biotechnol. 24, 31-39 (2006).

9. Evans, J. Am. J. Sociol. 116, 389-452 (2010).

10. Busch, L. et al. External Review of the Collaborative Research Agreement between Novartis Agricultural Discovery Institute, Inc. and The Regents of the University of California (Inst. Food and Agricultural Standards, Michigan State Univ., 2004); available at http://go.nature.com/sgocla. 